
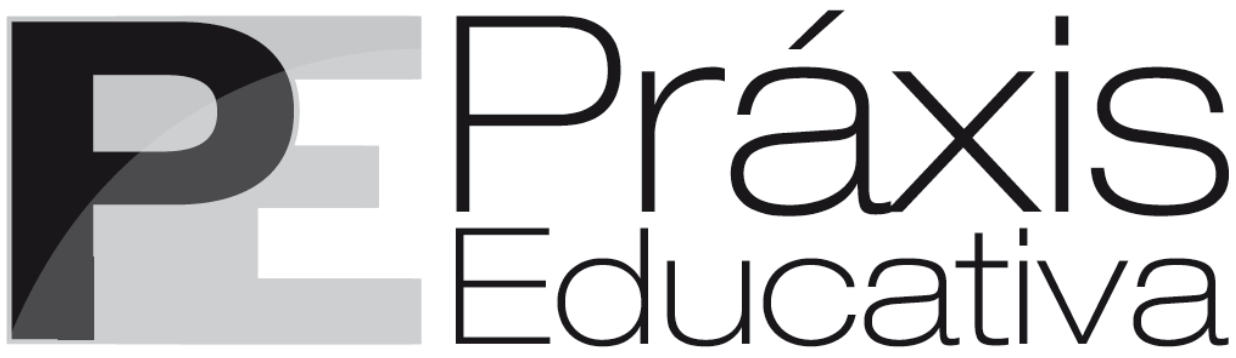

ISSN 1809-4031

elSSN 1809-4309

https://doi.org/10.5212/PraxEduc.v.16.16429.057

\title{
O legado de Paulo Freire ao desenvolvimento profissional docente para uma educação decolonial: o Círculo de Cultura como possibilidade
}

\section{Paulo Freire's legacy to professional teacher development for decolonial education: the Culture Circle as a possibility}

El legado de Paulo Freire al desarrollo profesional docente para una
educación decolonial: el Círculo de Cultura como posibilidad

Nilton Bruno Tomelin*

iD https://orcid.org/0000-0001-5501-5961

Rita Buzzi Rausch ${ }^{* *}$

(iD https://orcid.org/0000-0002-9413-4848

Resumo: Neste artigo, discute-se o legado de Freire em relação ao desenvolvimento profissional docente para uma educação decolonial, tomando como referência o Círculo de Cultura. De abordagem qualitativa e teórica, este texto tem Freire como principal teórico e, assim, relaciona suas ideias a de autores que tratam da formação de professores e da decolonialidade, ressignificando-as em uma perspectiva de docência outra. A investigação aborda a decolonialidade como proposta de construção de um futuro outro à profissão docente e aponta para sua proximidade com Freire. Propõe-se um desenvolvimento profissional docente que assuma a pluralidade cultural como fundamento para uma práxis efetivamente decolonial. Discute-se, também, o Círculo de Cultura a partir da reflexividade da prática, destacando-a como possibilidade ao desenvolvimento da consciência crítica e da transformação da ação docente. Em síntese, a pesquisa pretende fortalecer a potência do legado de Freire ao desenvolvimento profissional docente para uma educação decolonial.

Palavras-chave: Paulo Freire. Decolonialidade. Desenvolvimento profissional docente.

Abstract: In this article, Freire's legacy in relation to professional teacher development for a decolonial education is discussed, taking as a reference the culture circle. With a qualitative and theoretical approach, this text has Freire as its main theorist and, thus, relates his ideas to those of authors who deal with teacher training and decoloniality, re-signifying them in a different teaching perspective. The investigation addresses decoloniality as a proposal to build a different future for the teaching profession and points to its proximity

\footnotetext{
* Doutorando do Programa de Pós-Graduação em Educação da Universidade Regional de Blumenau (FURB). E-mail: $<$ niltonbt@sed.sc.gov.br>.

** Doutora em Educação pela Universidade Estadual de Campinas (Unicamp). Professora da Universidade Regional de Blumenau (FURB) e Universidade da Região de Joinville (UNIVILLE). E-mail: <ritabuzzirausch@gmail.com>.
} 
O legado de Paulo Freire ao desenvolvimento profissional docente para uma educação decolonial...

to Freire. It is proposed a professional teaching development that assumes cultural plurality as the basis for an effectively decolonial praxis. The Culture Circle is also discussed based on the reflexivity of the practice, highlighting it as a possibility for the development of critical awareness and the transformation of the teaching action. In summary, the research aims to strengthen the potency of Freire's legacy to the professional teacher development for a decolonial education.

Keywords: Paulo Freire. Decoloniality. Teacher professional development.

Resumen: En este artículo se discute el legado de Freire en relación al desarrollo profesional docente para una educación decolonial, tomando como referencia el círculo de la cultura. De enfoque cualitativo y teórico, este texto tiene a Freire como principal teórico, y así, relaciona sus ideas con las de los autores que tratan de la formación de los profesores y de la decolonialidad, resignificándolos en una perspectiva de docencia diferente. La investigación aborda la decolonialidad como propuesta para construir un futuro diferente para la profesión docente y apunta a su proximidad con Freire. Se propone un desarrollo profesional docente que asuma la pluralidad cultural como fundamento de una praxis efectivamente decolonial. También se discute el Círculo de Cultura a partir de la reflexividad de la práctica, destacándola como posibilidad para el desarrollo de la conciencia crítica y la transformación de la acción docente. En síntesis, la investigación pretende fortalecer la potencia del legado de Freire para el desarrollo profesional docente para una educación decolonial.

Palabras clave: Paulo Freire. Decolonialidad. Formación de profesores.

\section{Introdução}

A discussão do legado de Paulo Freire obviamente não cabe em um texto em torno de um tema, assim como sua extensão não pode ser medida pela temporalidade de seus escritos. Alguns conceitos, como consciência crítica, autonomia e liberdade, relacionados a maneiras outras de fazer-se humanidade e pensar o futuro, passam pelo que ele fez e pensou. Assim, ao apresentarmos a decolonialidade como uma alternativa concreta de libertação, por meio de uma análise crítica da realidade, a sua conquista dar-se-á a partir de um profundo inconformismo, por vezes convertido em indignação, de autores como Paulo Freire.

A proposição de um futuro e de uma humanidade decolonial não passa somente pela escola, mas esta poderá assumir seu protagonismo a depender da postura dos professores frente a esse desafio. A formação continuada de professores não pode permanecer alheia a essa nova demanda, visto que é por ela que a docência revigora seu compromisso com o que atinge crianças e adolescentes. Essa formação, por sua vez, exige uma nova configuração, sem as amarras da formação convencional em que alguém fala à docência e replica o que lhe é proposto. É tempo de darmos audiência à voz docente e construirmos uma práxis outra, desprovida de formatações, sustentada pela reflexão crítica de sua prática.

Nessa perspectiva, o objetivo, neste texto, é apontarmos o legado de Paulo Freire para o desenvolvimento profissional docente para uma educação decolonial, a partir do Círculo de Cultura. Do ponto de vista metodológico, refere-se a uma pesquisa teórica em que se propõe uma discussão da obra de Paulo Freire em interface com autores que tratam do desenvolvimento profissional docente e da teoria decolonial. Para Demo (1985), na pesquisa teórica, há três etapas fundamentais:

[...] o domínio dos clássicos de determinada disciplina. Eles trazem a acumulação já feita de conhecimento, as polêmicas vigentes, a cristalização de certas práticas de investigação, o ambiente atual da discussão em torno do assunto, e assim por diante. O conhecimento criativo dos clássicos - não a mera leitura passiva ou a de discípulo ingénuo - é uma das formas mais comuns de pesquisa teórica. [...] o domínio da bibliografia fundamental, através da qual tomamos conhecimento da produção existente; podemos aceitá-la, rejeitála e com ela dialogar criticamente. [...] a verve crítica [entusiasmada e criativa], através da

Práxis Educativa, Ponta Grossa, v. 16, e2116429, p. 1-17, 2021

Disponível em: <https://www.revistas2.uepg.br/index.php/praxiseducativa> 
qual instala-se a discussão aberta como caminho básico do crescimento científico. O bom teórico não é tanto quem acumulou erudição teórica, leu muito e sabe citar, mas principalmente quem tem visão crítica da produção científica, com vistas a produzir em si uma personalidade própria, que anda com os próprios pés. É mau teórico quem não passa do discípulo, do colecionador de citações, do repetidor de teorias alheias. (DEMO, 1985, p. 23-24).

Este estudo possibilitou que propuséssemos uma discussão crítica acerca do que está posto, em uma perspectiva de sugerirmos um diálogo entre autores para então estabelecermos uma nova perspectiva teórica. Nossa preocupação, aqui, não é a mera descrição de convergências ou divergências entre autores ou conceitos, mas lançamos um diálogo crítico em que convergências e divergências permitam identificar um possível legado de Freire para o desenvolvimento profissional docente para uma educação decolonial.

Assim, inicialmente, realizamos um estudo acerca do pensamento de Paulo Freire que o aproxima da teoria decolonial e do desenvolvimento profissional docente. Com isso, foi possível estabelecermos conceitos e concepções comuns ao pensamento freiriano, à teoria decolonial e ao desenvolvimento profissional docente, com ênfase no Círculo de Cultura. Dessa maneira, percebemos a importância do protagonismo da cultura, da reflexividade e do respeito à pluralidade de pensamentos, em detrimento de modelos hegemônicos impostos e distantes das diferentes realidades e formas de pensar, existir e viver.

Assim sendo, desejamos refletir sobre o pensamento de Paulo Freire e seu legado, partindo de sua vontade de ser constantemente reinventado, mas jamais imitado. Dito isso, neste texto, tratamos de Paulo Freire e sua relação com o conceito de decolonialidade, como caminho para uma educação outra, sendo inclusive identificado como um de seus precursores. Nesse sentido, abordamos o conceito de Círculo de Cultura relacionado ao desenvolvimento profissional, como estratégia para a formação de professores com vistas a uma educação decolonial. Dessa forma, valemo-nos das contribuições de Freire (1980a, 1980b, 1981, 1992, 1995, 1996, 2000, 2001, 2005, 2008) para compreender seu pensamento relativo ao tema proposto. Cortella (2011), Dussel (2000), Gadotti (1997) e Pontes e Di Giorgi (2020) sinalizam significativas reflexões acerca do legado de Freire. Freire e Betto (1985) e Romão et al. (2006) permitem-nos uma melhor compreensão do Círculo de Cultura. Acerca da temática da formação de professores, contamos com o pensamento de Imbernón (2009, 2010, 2011) e Nóvoa (1996, 2009); e com García (1999) e Ponte (1997) para tratar do desenvolvimento profissional docente. Sobre o conceito de decolonialidade, as contribuições de autores/estudiosos como Leite, Ramalho e Carvalho (2019), Mignolo (2003), Ocaña, Arias e Conedo (2018) e Walsh $(2009,2013)$ foram fundamentais.

Como veremos, a defesa de uma consciência crítica e a defesa dos oprimidos pode ser considerada um movimento precursor da decolonialidade. Em relação ao Círculo de Cultura, surgido nos movimentos da educação popular, trata-se de um valioso instrumento de consolidação de práticas dialógicas, essenciais ao desenvolvimento de uma educação decolonial.

O estudo teórico que propomos será descrito em três momentos distintos ao longo do texto. No primeiro momento, apontamos alguns indícios do pensamento de Paulo Freire nos alicerces da teoria decolonial, com ênfase na prática do Círculo de Cultura na experiência da educação popular. No segundo momento, partimos da prática do Círculo de Cultura articulado à formação de professores necessária à decolonialidade, o que implica uma perspectiva outra de desenvolvimento profissional docente. No terceiro, trazemos algumas considerações que materializam a relação entre o pensamento freiriano e a decolonialidade, com destaque para o protagonismo da cultura, do contexto e do próprio docente em sua formação.

Práxis Educativa, Ponta Grossa, v. 16, e2116429, p. 1-17, 2021

Disponível em: < https://www.revistas2.uepg.br/index.php/praxiseducativa> 
O legado de Paulo Freire ao desenvolvimento profissional docente para uma educação decolonial...

\section{Indícios decoloniais em Paulo Freire: o Círculo de Cultura e a experiência da educação popular como inspiração}

O termo "decolonialidade" é relativamente recente, tratado com ênfase a partir do final da década de 1990. Dessa forma, é compreensível que, na obra de Paulo Freire, o termo esteja ausente, porém não a sua essência. Ao contrário, parte substancial de sua obra é reconhecida como importante e imprescindível ao repertório teórico para compreendermos a decolonialidade como proposta de ruptura e de construção de um futuro outro. Antes de lançarmos a ideia do uso de Círculo de Cultura como estratégia para a formação de professores para uma educação decolonial, é preciso situarmos Paulo Freire no debate decolonial.

Nesse sentido, o estudo da obra de Paulo Freire e de alguns autores decoloniais sinaliza para uma relação convergente de abordagens e propósitos. Por essa razão, o tema da educação popular será abordado, para que seja possível ilustrarmos essas possíveis convergências. O estudo do conceito de educação popular permite, por sua vez, identificarmos elementos que sustentam a viabilidade, ou mesmo a necessidade, de utilizarmos o Círculo de Cultura em diferentes cenários do contexto educacional, inclusive no contexto da formação continuada de professores.

Diante disso, o estudo da obra de Paulo Freire permite-nos dizer que, mediante uma educação pautada em uma visão técnica, eurocêntrica e profundamente descontextualizada, propõe-se uma pedagogia crítica, problematizadora, contextual e de pergunta. Por meio dela, sugerem-se novos caminhos, diferentes daqueles estabelecidos por uma educação alheia à realidade e à participação e, por isso, descomprometida com o futuro dos que nela estão. Ao contrário, Freire, em seus escritos, denuncia a tendência de empreender-se uma certa inferioridade da cultura dita periférica em relação à hegemônica eurocêntrica.

Ocaña, Arias e Conedo (2018) apontam esses escritos e destacam a importância de Freire para a proposição decolonial de educação quando afirmam que:

Por su parte Pablo Freire, quien en muchos de sus escritos cita a Fanon, nos ha legado
una Pedagogía del Oprimido (1970) y una Pedagogía de la Autonomía (1996), obras
esenciales que se suman a La educación como práctica de la libertad (1969). Freire (1987,
$2011,2012 a, 2012 b, 2013 a, 2013 b, 2014)^{1}$ nos demuestra la importancia de leer y su
relación con el proceso de liberación. Sus obras son cartas de obligada lectura por parte
de quien pretenda enseñar. En sus libros se configuran saberes necesarios para la práctica
educativa decolonial, liberadora y emancipatoria. Aunque no utiliza las categorías
relacionadas con lo decolonial, nos regala una pedagogía de la esperanza. (OCAÑ;
ARIAS; CONEDO, 2018, p. 48).

A pedagogia da esperança não se configura em um mero desejo de que o futuro ofereça espontaneamente alguma perspectiva aos oprimidos, que carecem de liberdade e autonomia. Tratase de uma espera ativa e que, por isso, se converte em verbo: esperançar. Esperançar é, nesse viés, uma postura que sustenta o pensamento decolonial, como estratégia para mobilizar os que historicamente são submetidos a modelos legitimados por práticas silenciadoras. Sobre isso, Walsh (2009) evidencia as contribuições de Freire ao pensamento decolonial quando aponta, em muitos dos seus escritos, a clara preocupação com a desumanização produzida pela colonização.

Assim, Ocaña, Arias e Conedo (2018, p. 50) asseveram que "[...] el pensamiento de Freire ha sido muy útil para 'pedagogizar' de manera más explícita la decolonialidad y para engendrar,

\footnotetext{
1 Trata-se, respectivamente, das seguintes obras: "Justificativa da pedagogia do oprimido" em Pedagogia do oprimido; Pedagogía de la Esperanza. Un reencuentro con la Pedagogía del Oprimido; Pedagogía del Oprimido; Cartas a quien pretende enseñar, La educación como práctica de la libertad; La importancia de leer y el proceso de liberación; Pedagogía de la Autonomía. Saberes necesarios para la práctica educativa.
}

Práxis Educativa, Ponta Grossa, v. 16, e2116429, p. 1-17, 2021 Disponível em: < https://www.revistas2.uepg.br/index.php/praxiseducativa> 
nombrar y pensar con/desde las pedagogías decoloniales de resistencia y re-existencia". Trata-se de uma pedagogia fortemente comprometida com uma consciência crítica que consiste não apenas na ampliação da capacidade de reflexão dos colonizados, mas na mobilização desses sujeitos para construir seu próprio caminho rumo a um futuro outro, de profunda liberdade e libertação. De acordo com Dussel (2000, p. 443), Freire advoga que o "[...] ato pedagógico crítico se exerce no próprio sujeito e na sua práxis de transformação: a libertação assim é o lugar e o propósito desta pedagogia". Walsh (2013) corrobora essa concepção ao afirmar que Paulo Freire propõe uma forte relação entre o pedagógico e o decolonial, mirando para uma pedagogia que provocará uma leitura outra de mundo, como também uma reinvenção do pensar e do agir coletivos.

Essa reinvenção guarda forte relação com a da educação, que, por sua vez, pode relacionarse fortemente à atuação docente. Se há uma parte da docência comprometida com os ideais coloniais, há também outra parte disposta a fazer esse sistema ruir, porém carente de instrumentos que possam lhe oferecer um caminho outro para reinventar não um sistema, mas uma forma de educar que não aprisione, exclua ou silencie. Por isso, Ocaña, Arias e Conedo (2018) enfatizam que:

De ahí que los profesores debemos actuar de tal manera que podamos agrietar. Debemos aprovechar las grietas decoloniales. Las grietas decoloniales son inmanentes al método de enseñanza, las grietas emergen de nuestro accionar cotidiano, de nuestro modo de actuar decolonial, al estilo de Paulo Freire. (OCAÑA; ARIAS; CONEDO, 2018, p. 130).

Entretanto, a abertura dessas fissuras no contexto colonial, por si só, não representa uma garantia de espaço para posturas e vivências outras. Há uma tendência de esse sistema produzir rearranjos que conferem uma nova roupagem ao velho. Abertas as fissuras, torna-se imprescindível que sejam reveladas e denunciadas para que se mobilize um coletivo de atores que proponham algo outro. Para Leite, Ramalho e Carvalho (2019),

[...] o fim do período colonial na América Latina não significou o fim do colonialismo, já que seus traços persistiram ao tempo, chegando até os dias de hoje. É essa persistência da cultura colonial que Quijano chama de colonialidade. Tanto Quijano como Paulo Freire não só denunciam essa realidade de opressão: eles propõem uma ruptura com tal modelo, através de práticas decoloniais, nas palavras de Quijano, ou práticas libertadoras, na visão freiriana. (LEITE; RAMALHO; CARVALHO, 2019, p. 3).

A colonialidade e as suas relações precisam ser vistas como um problema e como geradoras de outros problemas, uma vez que, por elas, se produz uma legião de excluídos, subjugados e subalternizados. Do contrário, a escola assume um protagonismo inverso ao seu caráter transformador ao cumprir um triste e cruel roteiro de convencimento dos oprimidos, acerca da normalidade da sua condição, quando ainda não lhe impõe um certo grau de culpa por isso. Freire (2005, p. 67) afirma, por essa razão, que é preciso empreender uma educação outra, pois “[...] problematizar essa realidade, desmascarar os mecanismos da subalternização só é possível através de uma educação libertadora, que não esteja sob o controle dos opressores".

Essa educação outra e essencialmente libertadora constitui-se em um cenário de denúncia e também de anúncio. Denúncia da opressão que sinaliza uma ruptura imprescindível à superação do sistema colonial, e um anúncio que mira na possibilidade de que cada sujeito, imerso em um coletivo, poderá protagonizar uma forma outra de existir. A materialização da denúncia e do anúncio exige mais do que um discurso ou uma teorização. Logo, é necessário estabelecermos mecanismos para que denúncia e anúncio não sejam pronunciados por um único sujeito sobre os oprimidos, pois estaria replicando a prática colonial, na qual haveria um poder hegemônico, detentor do saber válido. Destarte, é fundamental que seja garantido um espaço de acolhida e de pronúncia coletiva à pluralidade de expressões, de sentidos e de sentimentos. Trata-se de garantir

Práxis Educativa, Ponta Grossa, v. 16, e2116429, p. 1-17, 2021

Disponível em: <https://www.revistas2.uepg.br/index.php/praxiseducativa> 
O legado de Paulo Freire ao desenvolvimento profissional docente para uma educação decolonial...

um cenário decolonial de discussões que Paulo Freire já adotou, desde os anos de 1960, quando fomentou a educação popular: o Círculo de Cultura.

A educação popular, proposta com o intuito de questionar a educação e a cultura elitista e excludente, sustentáculo do modelo colonial, propõe uma escola outra onde não seja necessário incluir, porque, por ser pública, não se admitirá ninguém e nenhum debate fora dela. O Círculo de Cultura torna-se imprescindível na educação popular, na medida em que, segundo Freire (1995, p. 16), "[...] a escola como um espaço de ensino-aprendizagem será então um centro de debates de ideias, soluções, reflexões, onde a organização popular vai sistematizando sua própria experiência". A educação popular está assim diretamente ligada a uma preocupação com a participação política das massas a partir da conscientização, passando a ser identificada como educação com as massas.

Leite, Ramalho e Carvalho (2019) relatam que foi nos anos de 1960 que vários coletivos de camponeses, artistas, intelectuais e estudantes se organizaram em movimentos populares, como o Movimento de Cultura Popular (MCP), do qual Paulo Freire fazia parte. Segundo os autores, coube à essa mobilização denunciar a exclusão vivida pelos sujeitos das camadas populares e o autoritarismo do Brasil de então. O protagonismo de Freire, nesse sentido, foi fundamental a partir de 1958, no II Congresso Nacional de Alfabetização de Adultos, quando propõe uma nova proposta para alfabetização de adultos, até então concebidos como incapazes e fracassados.

Freire aponta para o fracasso da escola, por não reconhecer e não conferir credibilidade à cultura popular presente no discurso dos analfabetos, insistindo em uma educação com seus pilares assentados em práticas hegemônicas e eurocêntricas. A educação popular é, portanto, a ruptura com o modelo que denominou de bancário e que é denunciado por ele como responsável por esse fracasso. Para Freire (2005):

\begin{abstract}
Na medida em que essa visão "bancária" anula o poder criador dos educandos ou o minimiza, estimulando sua ingenuidade e não criticidade, satisfaz aos interesses dos opressores: para estes, o fundamental não é o desnudamento do mundo, a sua transformação. O seu "humanitarismo", e não o seu humanismo, está em preservar a situação de que são beneficiários e que lhes possibilita a manutenção de sua falsa generosidade. (FREIRE, 2005, p. 69).
\end{abstract}

Dessa forma, a decolonialidade que parte desse desnudamento necessita de uma educação outra, humanitária, crítica e libertadora. Para tanto, é preciso rompermos definitivamente com a educação bancária, partindo do desvelamento de suas estratégias de perpetuação, que, de acordo com Freire (2005), são: a conquista em que há um sujeito conquistador e outros conquistados e convertidos em coisas; a divisão entre os sujeitos coisificados que se veem como inimigos a serem abatidos pela competição e por processos classificatórios; a manipulação pela qual as elites convencem os oprimidos a defender suas causas por meio de uma educação antidialógica, impedindo as massas populares de pensar; a invasão cultural que tem como finalidade invisibilizar a cultura popular, impondo a cultura da elite como a legítima. Paulo Freire reconhecia nessa última estratégia a mais perversa e com consequências devastadoras para o oprimido. Por isso, Freire (2005) afirma que:

Na medida em que os invadidos vão reconhecendo-se "inferiores" necessariamente irão reconhecendo a "superioridade" dos invasores. Os valores destes passam a ser a pauta dos invadidos. Quanto mais se acentua a invasão, alienando o ser da cultura e o ser dos invadidos, mais estes quererão parecer com aqueles: andar como aqueles, vestir à sua maneira, falar a seu modo. (FREIRE, 2005, p. 175).

Com isso, Paulo Freire denuncia a usurpação de direitos que culmina na destruição da identidade dos oprimidos, no momento em que a escola ignora a cultura e o conhecimento popular. Assume-se, assim, um caráter elitista e excludente, partindo da subalternização da cultura e do saber

Práxis Educativa, Ponta Grossa, v. 16, e2116429, p. 1-17, 2021

Disponível em: < https://www.revistas2.uepg.br/index.php/praxiseducativa> 
popular. Freire (1992, p. 86) assevera que “[...] o respeito, então, ao saber popular implica necessariamente o respeito ao contexto cultural. A localidade dos educandos é o ponto de partida para o conhecimento que eles vão criando do mundo. 'Seu' mundo, em última análise é a primeira e inevitável face do mundo mesmo". Desse modo, está claro que a cultura precede a educação e que todo o processo de mudança, inclusive para a decolonialidade, necessariamente se sustenta na forma como se concebe o lugar das diferentes culturas no cenário de formação humana.

Como forma de estabelecer o lugar das culturas em um coletivo, Paulo Freire propôs a metodologia do Círculo de Cultura. O Círculo, do latim circulus (redondeza), é utilizado para definir a forma da estratégia utilizada que permite a circulação dos seres, dos saberes e dos sentimentos das pessoas. As pessoas são dispostas em círculo para que não haja lugar privilegiado e que todos possam sentir-se em igualdade de condições para participar dos diálogos e das discussões acerca de problemas e temas gerados a partir da realidade vivida e experimentada pelos participantes.

Freire (1980a) afirma que os Círculos de Cultura são centros em que o povo discute os seus problemas e constrói coletivamente ações para solucioná-los. Dessa forma, o Círculo de Cultura estabelece entre os participantes uma profunda reflexão crítica sobre suas realidades e vivências cotidianas, a qual pode subsidiar ações educativas. Freire (1981, p. 19) sugere, como exemplo, que "[...] todas estas reações orais que se vão dando durante as discussões nos Círculos de Cultura, devem ser transformadas em textos que, entregues aos alfabetizandos, passam a ser por eles discutidos". Nesse contexto, não há propriamente um professor, mas um coordenador a quem cabe estabelecer o diálogo e relatar o que é discutido, intervindo minimamente.

Nessa discussão, manifestam-se culturas e, por meio do diálogo, cada sujeito se reconhece como detentor, comunicador e produtor de cultura. Segundo Freire (2008),

[...] a cultura como o acrescentamento que o homem faz ao mundo que não fez. A cultura como o resultado de seu trabalho. De seu esforço criador e recriador. O sentido transcendental de suas relações. A dimensão humanista da cultura. A cultura como aquisição sistemática da experiência humana. Como uma incorporação, por isso crítica e criadora, e não como uma justaposição de informes ou prescrições "doadas". (FREIRE, 2008, p. 117).

A importância da cultura e de seu protagonismo como autora e terreno de transformação e libertação é exaltada em outro texto em que Freire (2000) manifesta que:

\begin{abstract}
Se a mudança faz parte necessária da experiência cultural, fora da qual não somos, o que se impõe a nós é tentar entendê-la na ou nas suas razões de ser. Para aceitá-la ou negá-la devemos compreendê-la, sabendo que, se não somos puro objeto seu, ela não é tampouco o resultado de decisões voluntaristas de pessoas ou de grupos. Isto significa, sem dúvida, que, em face das mudanças de compreensão, de comportamento, de gosto, de negação de valores ontem respeitados, nem podemos simplesmente nos acomodar, nem também nos insurgir de maneira puramente emocional. É neste sentido que uma educação crítica, radical, não pode jamais prescindir da percepção lúcida da mudança que inclusive revela a presença interveniente do ser humano no mundo [...]. Da mudança em processo, no campo dos costumes, no do gosto estético de modo geral, das artes plásticas, da música, popular ou não, no campo da moral, sobretudo no da sexualidade, no da linguagem, como da mudança historicamente necessária nas estruturas de poder da sociedade, mas a que dizem não, ainda, as forças retrógradas. (FREIRE, 2000, p. 17).
\end{abstract}

É inquestionável, portanto, que a prática do Círculo de Cultura é um caminho para a decolonialidade, apontado por Paulo Freire mesmo antes que se falasse dela com essa denominação. Trata-se de uma contribuição que transcende seu tempo para que, como ele próprio propunha, não seja imitado, mas reinventado. A propósito, a inserção de Círculo de Cultura na perspectiva de uma formação continuada de professores para uma educação decolonial revela-se

Práxis Educativa, Ponta Grossa, v. 16, e2116429, p. 1-17, 2021

Disponível em: < https://www.revistas2.uepg.br/index.php/praxiseducativa> 
O legado de Paulo Freire ao desenvolvimento profissional docente para uma educação decolonial...

como uma forma de reinventar Freire, tornando-o presente em um debate que se quer desafiador às formas já conhecidas.

\section{Desenvolvimento profissional docente decolonial a partir do Círculo de Cultura}

O estudo do legado de Paulo Freire para o desenvolvimento profissional docente para uma educação decolonial, compreendida como a relação entre o seu pensamento e a decolonialidade, lança o desafio de inserirmos o Círculo de Cultura como estratégia. Especificamente, ao abordarmos a formação continuada de professores, é relevante destacarmos que o Círculo de Cultura não é apenas uma estratégia de organização dessa formação, mas um possível caminho de investigação que acenará para suas principais demandas.

Nesse sentido, a materialização da prática do Círculo de Cultura no contexto educacional exige, além da compreensão de que a cultura precede a educação, um docente comprometido com uma práxis outra, que se contraponha à subserviência da escola a sistemas e modelos hegemônicos, silenciadores e opressores. Considerando que os professores são oriundos de uma sociedade e de uma escola (universidade) que privilegia o que essa práxis outra se contrapõe, é preciso uma formação pautada na participação do coletivo dos professores. Como boa parte dos professores provém das classes populares, a participação do professor em seu processo de formação implica o protagonismo da cultura popular na definição da mencionada práxis. Para Freire (1980b, p. 38), "[...] a cultura é todo o resultado da atividade humana, do esforço criador e recriador do homem, de seu trabalho por transformar e estabelecer relações de diálogo com os outros homens".

Por essa razão, com o Círculo de Cultura, a participação torna-se sinônimo de protagonismo e autoria. Conforme Freire (2001) disserta:

Para nós, a participação não pode ser reduzida a uma pura colaboração que setores populacionais devessem e pudessem dar à administração pública. [...]. Implica, por parte das classes populares, um "estar presente na História e não simplesmente nela estar representadas”. Implica a participação política das classes populares através de suas representações, no nível das opções, das decisões e não só do fazer o já programado. (FREIRE, 2001, p. 75).

Dito isso, é preciso lembrar que, ao tratar-se de formação permanente, se está propondo um processo formativo de quem já acumula certa experiência na docência. Por isso, Freire (1996, p. 39) considera que "[...] na formação permanente dos professores, o momento fundamental é o da reflexão crítica sobre a prática. É pensando criticamente a prática de hoje ou de ontem que se pode melhorar a próxima prática". Nóvoa (1996), importante estudioso do campo da formação de professores, na contemporaneidade, afirma que:

\footnotetext{
$\mathrm{Na}$ América do Norte, Paulo Freire circula nos meios acadêmicos e universitários, constituindo uma referência importante dos grupos que colocam no programa político (e educacional) as questões de classe, de raça e de gênero. Curiosamente, a análise específica das "minorias" não é presente nos primeiros escritos de Freire. Mais, o que mais chama a atenção dos intelectuais (e militantes) do "primeiro" mundo é a sua posição de princípio contra toda forma de discriminação social. Através da articulação entre a "linguagem da crítica" e uma "linguagem de possibilidade", ele abre perspectivas de ação sem, entretanto, cair numa atitude inocente e desengajada. (NÓVOA, 1996, p. 54).
}

Essa relação entre crítica e possibilidade é o que fundamenta a prática do Círculo de Cultura que, por meio do diálogo horizontalizado, tece críticas ao modelo hegemônico, provocando as fissuras mencionadas anteriormente, porém apontando possibilidades. Conforme Imbernón (2009), no que diz respeito à formação continuada de professores, é preciso: 
Criar estruturas (redes) organizativas que permitam um processo de comunicação entre os pares e intercâmbio de experiências para possibilitar a atualização em todos os campos de intervenção educativa e aumentar a comunicação entre o professorado para refletir sobre a prática educativa mediante a análise da realidade educacional, a leitura pausada, o intercâmbio de experiências, os sentimentos sobre o que acontece, a observação mútua, os relatos de vida profissional, os acertos e os erros... que possibilitem a compreensão, a interpretação e a intervenção sobre a prática. (IMBERNÓN, 2009, p. 40-41).

O Círculo de Cultura apresenta-se como uma estrutura capaz de contemplar, em um contexto de formação continuada, a necessidade de comunicação e reflexão em um grupo de sujeitos que desejem propor uma realidade outra ao seu coletivo. Ele toma o lugar da formação continuada em que alguém, por vezes alheio ao contexto, propõe algo pensado e refletido para ser implementado como estratégia de intervenção. Um projeto de contexto outro exige participação daqueles que o vivem e conhecem suas agruras e suas possibilidades desde sua reflexão, discussão, para que seja implementado e assumido com o necessário comprometimento.

Para sedimentar a possível participação da prática do Círculo de Cultura na formação de professores, Freire e Frei Betto (1985) afirmam que:

O círculo de cultura era uma experiência em que você trabalhava com duas, três ou até vinte pessoas, não importava. Os projetos dos círculos de cultura do MCP não tinham uma programação feita a priori. A programação vinha de uma consulta aos grupos, quer dizer: os temas a serem debatidos nos círculos de cultura, o grupo que estabelecia. Cabia a nós, como educadores, com o grupo, tratar a temática que o grupo propunha [...]. Porque acontece o seguinte: é que, indiscutivelmente, há uma sabedoria popular, um saber popular que se gera na prática social de que o povo participa, mas, às vezes, o que está faltando é uma compreensão mais solidária dos temas que compõem o conjunto desse saber. (FREIRE; FREI BETTO, 1985, p. 14-15).

A compreensão dos saberes oriundos da cultura característica desse grupo - um grupo popular - é fundamental para a formação continuada de professores, uma vez que a maioria deles provém também desse grupo, e, no caso da educação pública, o atinge diretamente. É possível notarmos que, na prática do Círculo de Cultura, não se vai à academia em busca de saberes, mas à experiência humana, vivida e sentida. Assim, propomos que uma das funções essenciais da educação às novas gerações, por meio do (re)conhecimento dessa experiência como forma de superar a consciência ingênua da realidade, é estabelecer uma leitura crítica de sua própria condição. Para Freire (2005), o oprimido é mantido em sua condição pela supremacia da ingenuidade em sua forma de ler o mundo e sua superação se dá em dois momentos, mirando para uma pedagogia libertadora:

O primeiro, em que os oprimidos vão desvelando o mundo da opressão e vão comprometendo-se, na práxis, com a sua transformação; o segundo, em que transformada a realidade opressora, esta pedagogia deixa de ser do oprimido e passa a ser pedagogia dos homens em processo permanente de libertação. (FREIRE, 2005, p. 45).

A pedagogia libertadora opõe-se à consciência ingênua que aposta na interpretação simplista dos problemas, estudando o fato de forma superficial e apressada. Ademais, a percepção ingênua da realidade tende a promover a massificação de comportamento, que, por vezes, instiga o fanatismo, além de demonstrar fragilidade na construção de argumentos e valer-se de autoritarismo, impondo ideias que efetivamente não compreende. Em oposição a esse quadro, Freire (2005) oferece a consciência crítica como caminho para sua superação. Por meio dela, os problemas são analisados com profundidade em uma perspectiva de mutabilidade da realidade; procura compreender as razões históricas dos fatos; nega toda a forma de preconceito; é inquieta e torna-se mais crítica quanto mais reconhece sua inquietude; costuma ser indagadora, investigativa, conflitante e dialógica. 
O legado de Paulo Freire ao desenvolvimento profissional docente para uma educação decolonial...

Dessa forma, notamos que a preocupação é com uma aprendizagem não limitada ao contexto, mas, sim, que parte dele e, também, busca aprofundar a leitura sobre ele, para, então, retornar e intervir. Essa intervenção acentua-se na medida em que atinge o próprio sujeito aprendente, intervindo na sua forma de ser, de oprimido a autor de sua própria história. Além disso, todo esse processo não se dá de forma individualizada, mas parte da vivência individual e alcança suas relações com os outros, sempre considerando o pressuposto freiriano de que ninguém se educa sozinho, mas com os demais mediatizados pelo mundo.

Portanto, essa prática reflexiva será possível e viável quando realizada coletivamente por aqueles que assumem o desafio de mudar e melhorar sua própria prática. Essa preocupação tem sido notada nas universidades, nos cursos de formação docente, que, segundo Imbernón (2010), aponta para uma tendência de desenvolverem-se alternativas à formação docente, que se distancie de modelos tradicionais e busque, na reflexão da prática, uma excelente oportunidade de fomentar uma nova perspectiva de desenvolvimento da docência. O autor destaca a importância da pesquisaação como mecanismo desencadeador desse processo e exalta que a participação do professor em sua formação o compromete em desenvolver uma prática pedagógica participativa junto a seus alunos.

O Círculo de Cultura pode representar uma excelente oportunidade para que docentes estabeleçam um novo horizonte formativo, partindo da reflexão de suas próprias demandas. Ao considerarmos a diversidade de problemáticas emanadas pelos participantes, é possível dizermos que a consolidação do legado freiriano, no que diz respeito ao desenvolvimento profissional docente, não se limita à estruturação de uma prática formativa de Círculo de Cultura, mas parte e se espraia com base nas mudanças no cenário da gestão escolar. Os gestores, vistos não apenas como administradores escolares, precisam reinventar cotidianamente seu protagonismo e perceberse como parte fundamental no processo de formação da docência. Por isso, Pontes e Di Giorgi (2020) são categóricos ao afirmar que:

No âmbito da formação continuada, requer mudança na concepção de educação escolar
por parte dos gestores educacionais da macro e da microesfera, o que implica, entre
outras coisas, a abertura da gestão educacional à construção coletiva dos conteúdos
programáticos destinados à formação continuada de professores. Ainda nesse segmento,
é necessária a implementação curricular dos programas e cursos de formação docente
com a integração da obra de Paulo Freire nos referenciais teóricos, além do planejamento
do tempo a ser destinado a estudos da obra freiriana. (PONTES; DI GIORGI, 2020, p.
137).

Logo, a inserção do pensamento freiriano na consolidação de novas perspectivas para formação continuada de professores torna-se não somente viável, mas necessária à práxis que, por vezes, se distancia do cotidiano. Assim, a discussão do cotidiano a partir da prática do Círculo de Cultura pode ser o ponto de partida para um percurso contínuo de (re)construção ancorada em princípios dialógicos, críticos e, também, científicos.

Essa proposição que encaminha para uma nova perspectiva de desenvolvimento profissional docente, com vistas a uma educação decolonial, sugere que o legado freiriano não se resume a assumir sua pedagogia, ler seus escritos ou seguir uma metodologia. Ao contrário, sua pedagogia, como também seus escritos e suas indicações metodológicas, serve de inspiração para uma constante reinvenção em direção à uma pedagogia outra, instituída a partir da participação coletiva no Círculo de Cultura. O legado, nesse sentido, pode ser percebido pela discussão em torno da necessária compreensão de que a escola não é apenas um edifício em que se ministram aulas. A escola é o conjunto de pessoas que estão nela, mas não somente nela, pois elas estão com suas culturas, suas vivências, seus conflitos, seus sonhos.

Práxis Educativa, Ponta Grossa, v. 16, e2116429, p. 1-17, 2021

Disponível em: < https://www.revistas2.uepg.br/index.php/praxiseducativa> 
Assim sendo, com essa nova concepção de educação, demanda-se um novo docente, que não apenas conheça a teoria que a fundamenta, mas principalmente as práticas que permitem materializá-la junto aos que historicamente se encontram à margem. Dessa forma, propor um desenvolvimento profissional docente por meio da prática do Círculo de Cultura pode oferecer elementos concretos para consolidar uma nova práxis, que, em outras palavras, representa uma importante etapa de sua formação profissional. Na concepção de Ponte (1997),

[...] corresponde a um processo de crescimento na sua competência em termos de práticas lectivas e não lectivas, no autocontrolo da sua atividade como educador e como elemento activo da organização escolar. O desenvolvimento profissional diz assim respeito aos aspectos ligados à didáctica, mas também à acção educativa geral, aos aspectos pessoais e relacionais e de interacção com os outros professores e com a comunidade extraescolar. (PONTE, 1997, p. 44).

Dada a complexidade inerente ao desenvolvimento profissional docente, sua aproximação com Freire não é fruto do acaso, pois seu pensamento privilegia a interatividade, o diálogo e o respeito à diversidade. Essa aproximação torna-se fundamental quando, com base em García (1999), entendemos que o desenvolvimento profissional docente se dá em toda a sua trajetória, iniciada antes de sua formação inicial. Uma formação docente que não considere a historicidade do sujeito, lhe oferece conhecimentos, sem que estes efetivamente lhe garantam um acréscimo à sua existência profissional ou pessoal.

Por isso, Imbernón (2011, p. 45) assevera que “[...] o desenvolvimento profissional é um conjunto de fatores que possibilitam ou impedem que o professor progrida em sua vida profissional". Para que esse progresso seja efetivo e que o docente se insira em um processo de desenvolvimento profissional é fundamental que dialogue com seus pares, estabelecendo com eles construções críticas em nível prático e teórico. Sem isso, a vida profissional docente resume-se a replicar modelos teóricos e práticos, sem que haja efetivamente desenvolvimento no âmbito da profissão. Há como que uma sucessão de etapas já previstas ao longo da carreira, já vividas por outros docentes, sem que haja efetivamente uma nova carreira em cada professor.

Gadotti (1997), ao descrever parte do legado de Paulo Freire, afirma que este nos deixou uma imensa obra, em forma de livros, artigos e vídeos nos quais propõe uma pedagogia revolucionária, que privilegia o diálogo e preza pela dignidade do aluno, mirando o professor como um parceiro seu. Para o autor, Freire desmistificou os sonhos do pedagogismo dos anos de 1960 que era absolutamente ingênuo e permissivo e ajudou a superar o pessimismo dos anos de 1970, mantendo-se fiel à utopia, sonhando sonhos possíveis.

A utopia e os sonhos são a expressão mais substancial daquilo que conhecemos como transcendência. São eles que descrevem os desafios, as transformações e o impossível do agora. Negarmos essa transcendência é entregarmos a história ao mecanicismo da repetição de práticas que a modernidade se encarregou de reeditar. Ao contrário disso, em uma perspectiva transcendente, é preciso reconhecermos que se vive um processo, a historicidade, o qual é percebido pela própria ciência que frequentemente se reconhece inacabada, mutável e em busca de novas perguntas para que as novas respostas determinem o inédito, que será alvo de novas perguntas.

O pensamento de Paulo Freire inscreve-se nessa lógica, atualizando-se pela própria transformação gerada pela sua necessária reinvenção diante da necessidade de não repetir ciclos históricos. Essa necessidade nasce do desejo de Paulo Freire de acolher os esfarrapados, excluídos e oprimidos que a história produziu. A presença de Freire é um esperançar revolucionário diante da insistente prática conservadora e reacionária que tem regido nossa história. Por isso, Cortella (2011) afirma que: 
O legado de Paulo Freire ao desenvolvimento profissional docente para uma educação decolonial...

O pensamento de Paulo Freire é novo, a música de Mozart é nova, a obra de Platão é nova, Catulo da Paixão Cearense é novo. Por quê? Porque o seu trabalho não perdeu vitalidade, não perdeu a irrigação, não perdeu a conexão com a vida e com o sangue que a vida partilha e emana. Desse ponto de vista, o pensamento de Paulo Freire é absolutamente atual, no sentido de guardar a sua forma de ser novo. Ele não é novidade. A novidade é passageira, é fluida, ela escorre. Ele permanece. (CORTELLA, 2011, p. 11).

Dessa forma, inserir a prática freiriana do Círculo de Cultura na formação continuada de professores é dar continuidade, sem o risco da mera repetição, ao processo histórico de desenvolvimento profissional docente. Não há como pensarmos em nova docência sem transcendermos aos modelos vigentes e cristalizados. Nessa perspectiva, a prática freiriana apresenta-nos convites, como o Círculo de Cultura, a fazermos um novo caminho. Para esse caso específico, a formação dos professores a partir do Círculo de Cultura pode ser considerada como fruto de um legado freiriano - um legado na autêntica acepção freiriana do termo. A prática do Círculo de Cultura inspira-nos não somente uma mudança pontual da prática, mas também a desenvolvermos pesquisa com e sobre ela, para tratar de seus impactos no desenvolvimento profissional docente. Fazer pesquisa e comunicá-la é fundamental para que boas práticas (libertadoras, críticas, dialógicas) não sejam apenas atos isolados, mas tornem-se objeto de profunda discussão e constante transformação. Essa pesquisa não ocorre de forma dissociada da prática, mas tendo nela e na reflexão sobre ela seu principal objeto, conforma anuncia Freire (2005) ao salientar que

[...] os homens que, através de sua ação sobre o mundo, criam o domínio da cultura e da história, está em que somente estes são seres da práxis. Práxis que, sendo reflexão e ação verdadeiramente transformadora da realidade, é fonte de conhecimento reflexivo e criação. [...] os homens, simultaneamente, criam a história e se fazem seres históricosociais. (FREIRE, 2005, p. 92).

Assim, uma formação docente que inspire para o desenvolvimento de uma nova docência, e, por consequência, uma educação outra, passa pelo desejo do próprio docente em ser pesquisador, utilizando sua prática e seu contexto, como pode ocorrer no Círculo de Cultura. Por essa razão, em uma perspectiva de ampliar o desenvolvimento profissional docente, Nóvoa (2009) reforça a necessidade de os docentes atuarem decisivamente acerca de sua própria formação. Recordando o postulado freiriano de que a cultura precede a educação (incluindo aí a pesquisa em Educação), a instituição de uma formação continuada de professores, com essa roupagem, representa uma nova dimensão epistemológica descrita por Romão et al. (2006). Os autores afirmam que:

A denominação de "círculo epistemológico", para a metodologia de pesquisa derivada, é conveniente, não apenas para distinção de sua fonte, que é o Círculo de Cultura, formulado por Paulo Freire para intervenção, mas, também e principalmente, pela consideração dos "pesquisados" como sujeitos da pesquisa. Neste sentido, preserva o princípio freiriano de que todos, no círculo, pesquisando e pesquisadores, são sujeitos da pesquisa que, enquanto pesquisam, são pesquisados e, enquanto são investigados, investigam. É por esta mesma razão que a expressão "O(a)" é substituído por "O(a) pesquisando(a)". Os(as) pesquisando(as) não são apenas objeto da pesquisa, alvo da análise e da enunciação alheia, mas também sujeitos e lugares de análise e enunciação. (ROMÃO et al., 2006, p. 177-178).

Nesse cenário epistemológico, é possível vislumbrarmos a decolonialidade implícita à prática do Círculo de Cultura também na formação continuada de professores, como um elemento que sinaliza para o momento em que o docente não será apenas aprendiz, mas pelo diálogo crítico e pelas relações estabelecidas, igualmente autor do estudo e da projeção de sua prática. Segundo Dussel (2000), Freire propõe uma educação que parte da vítima do processo histórico, para que esta deixe de sê-lo, definindo novos rumos a esse processo. Trata-se de uma prática em que o

Práxis Educativa, Ponta Grossa, v. 16, e2116429, p. 1-17, 2021

Disponível em: < https://www.revistas2.uepg.br/index.php/praxiseducativa> 
conhecimento é posto horizontalmente em ação para a resolução de problemas e não como mera resposta a uma pergunta.

Dessa maneira, o desenvolvimento profissional docente pela prática do Círculo de Cultura, para uma educação decolonial, apresenta-se como uma proposta transformadora. Além disso, aprofunda conhecimentos e produz outros para que a formação continuada de professores seja pensada como estratégia fundamental para a transformação necessária a uma educação outra, de modo a acentuar a atualidade e a essencialidade do legado freiriano.

A proposição de uma formação que corrobore uma educação decolonial e a necessidade de o docente constituir-se pesquisador é, sem dúvida, um desafio derivado do pensamento freiriano de fazer da educação um instrumento de libertação e de crítica à realidade. Uma crítica que não apenas redefina conceitos, mas os supere e constitua novos, sinalizando para perspectivas outras. Ademais, não há dúvidas de que o modelo de educação que temos é insatisfatório e que estamos diante de uma crise, visto que a educação do século XXI não comporta e reivindica uma escola outra, um docente outro. Paulo Freire já enunciava e anunciava a necessidade de profundas mudanças, partindo das pessoas e dos espaços em que a educação desenvolve seu protagonismo, o que significa uma profunda ruptura.

Derivados disso, a insatisfação e o cenário de crise estendem-se também sobre os atuais modelos de formação continuada de professores, que culminam por desenvolver um exercício profissional docente conivente com a escola que exclui culturas e saberes. Uma escola que condena à marginalização tudo e a todos que não se formatam aos modelos hegemônicos. Por isso, Freire (1996) propõe uma escola em que os educandos vão se tornando autores da construção e da reconstrução do saber ensinado, assim como o educador se torna igualmente sujeito do processo.

Propor uma formação partindo de um discurso e de uma prática alheia ao contexto vivido e presenciado pelo docente não estabelece qualquer avanço no que diz respeito ao desenvolvimento e à qualificação da ação docente em favor de sua autoria ou a dos educandos. A docência não carece de modelos que lhe sejam oferecidos, mas de oportunidades de dizer a sua palavra e o seu mundo e ouvir os dos seus pares, o que caracteriza a imprescindível reflexividade da prática docente.

Logo, é preciso reiterar que o pensamento de Paulo Freire e a decolonialidade possuem semelhanças plurais e, no que diz respeito ao desenvolvimento profissional docente, o reconhecimento da capacidade cognitivo-epistêmica é uma delas. Outra é o distanciamento das convicções históricas hegemônicas, em busca de um caminho distante dos grandes centros pensantes. Com isso, conduz-se o desenvolvimento da profissão docente, por meio do que os decoloniais chamam de pensamento de fronteira, a uma reflexão outra, não apenas sugerindo uma nova compreensão do pensamento hegemônico, mas a elaboração de pensamentos outros. Para Mignolo (2003), o pensamento de fronteira constitui-se como uma possibilidade outra ao universalismo cognitivo, construído no contexto do eurocentrismo. Podemos dizer que a profissão docente terá uma alternativa à simples adesão a modelos, podendo constituir uma caminhada própria, não preestabelecida e construída ao caminhar. Essa caminhada, segundo Freire (1992), se materializa

[...] fazendo-se e refazendo-se no processo de fazer história, como sujeitos e objetos, mulheres e homens, virando seres da inserção no mundo e não da pura adaptação ao mundo, terminaram por ter no sonho também um motor da história. Não há mudança sem sonho como não há sonho sem esperança. (FREIRE, 1992, p. 91).

O respeito pelas diferentes vivências e pela forma como se processam revelam com maior contundência o protagonismo histórico de Paulo Freire em relação à decolonialidade, que poderá inspirar uma nova forma de fazer docência, desvinculada de modelos ou formatos definidos. Uma

Práxis Educativa, Ponta Grossa, v. 16, e2116429, p. 1-17, 2021

Disponível em: < https://www.revistas2.uepg.br/index.php/praxiseducativa> 
O legado de Paulo Freire ao desenvolvimento profissional docente para uma educação decolonial...

forma já experimentada e teorizada por Freire, na qual o processo se estabelece na medida em que ele acontece por meio de uma constante análise crítica do contexto e da práxis, que implica necessariamente um exercício de permanente reflexividade.

\section{Considerações finais}

Conforme enunciamos, o propósito deste estudo foi apontar o legado de Paulo Freire ao desenvolvimento profissional docente para uma educação decolonial, a partir do círculo de cultura. Este é um dos muitos legados de Paulo Freire, não apenas à Educação, mas para a construção de uma sociedade em que todos possam viver e existir da forma como desejam, tendo como limites, o respeito, a vivência e a existência dos outros conforme desejam.

Inicialmente percebemos que um grande legado de Paulo Freire é o fato de ser um importante precursor da teoria decolonial, uma vez que, desde os anos de 1960, procura-se estabelecer os postulados fundantes da educação popular, dentre os quais está o Círculo de Cultura. Nesse contexto, Freire nos desafia para o esperançar como estratégia para mobilizar os oprimidos, esfarrapados e subalternizados. Sua pedagogia dialógica, crítica e libertadora provoca uma leitura outra de mundo, como também uma reinvenção do pensar e agir coletivos.

Ao lado de pensadores como Aníbal Quijano, Freire denuncia que o fim do período colonial não implica necessariamente no fim do colonialismo e da colonialidade. Ao contrário, chegamos ao século XXI com uma legião de excluídos, subjugados e subalternizados. Nesse contexto, Quijano propõe outro importante legado freiriano que é a exaltação do caráter transformador da escola, especialmente por meio de uma educação problematizadora que, por sua vez, necessita de uma docência sensível à problemática do contexto em que a escola se situa.

Ao apostar no Círculo de Cultura, Freire define o protagonismo da cultura na determinação dos caminhos da educação. Freire aponta para o fracasso da escola tradicional de prática denominada por ele de "bancária", por não reconhecer e não conferir credibilidade à cultura popular e ao privilegiar práticas hegemônicas e eurocêntricas. A educação popular, por configurar uma ruptura com esse modelo que denominou de bancário, aponta para o legado de Freire à decolonialidade. Dessa forma, Freire denuncia a destruição da cultura dos oprimidos, no momento em que a escola ignora a cultura e o conhecimento popular.

Ao considerarmos que boa parte dos professores provém das classes populares, é fundamental a sua participação em seu processo de formação, o que implica o protagonismo da cultura popular na definição da práxis e no desenvolvimento profissional docente. O Círculo de Cultura é interessante para a formação continuada de professores porque se baseia no diálogo que horizontaliza as relações e as discussões entre os participantes. Trata-se de uma alternativa para que o desenvolvimento profissional docente se distancie de modelos tradicionais e hegemônicos e assuma a pluralidade de culturas e pensamentos implícitos no conjunto dos docentes.

Paulo Freire procurou constituir uma nova identidade à docência, não a reduzindo a mera elaboração e execução de aulas. Propunha assim uma docência capaz de construir junto à realidade em que se situa elementos de formação para que os sujeitos possam tonar-se agentes de intervenção. Por isso, há a necessidade de propor-se uma formação continuada de professores que não seja mera réplica de discursos e práticas já fragilizados por seus resultados, mas que parta de um novo processo histórico de desenvolvimento profissional docente, com base na crítica e na ruptura em relação a essas práticas. Além da mudança da prática docente, essa formação inspira a pesquisa com e sobre ela, para tratar de seus impactos no desenvolvimento profissional docente. Assim, a formação continuada por meio do Círculo de Cultura propõe a busca de soluções para

Práxis Educativa, Ponta Grossa, v. 16, e2116429, p. 1-17, 2021

Disponível em: < https://www.revistas2.uepg.br/index.php/praxiseducativa> 
problemas mais complexos, como a subordinação do fazer docente à colonialidade, visando a transformação da realidade. Se realizada de outra forma, a formação continuada de professores poderá constituir um novo marco teórico para o desenvolvimento profissional docente.

Tudo isso será possível ao adotarmos outro legado freiriano: a reflexividade sobre a prática. Reflexividade que evoca a necessidade de o docente superar em si e em seu contexto a consciência ingênua para assumir uma consciência crítica, para que em sua práxis possa fortalecer nos educandos esse mesmo desejo libertador. Por meio dessa passagem é que o pensamento hegemônico é identificado e criticamente superado para que se estabeleça a necessária pluralidade de culturas e pensamentos. Por intermédio dessa pluralidade é que rompemos com a opressão característica do modelo hegemônico eurocêntrico. Buscando um caminho distante dos grandes centros pensantes, essa pluralidade lança o desenvolvimento da profissão docente no que os decoloniais chamam de pensamento de fronteira. Desse modo, caminhamos para uma nova docência desvinculada de modelos ou formatos definidos, mas partindo de um caminhar junto aos que historicamente não cabem nesses modelos.

Trata-se de uma contribuição valiosa de Paulo Freire, dentre tantas descritas e materializadas em diferentes áreas do conhecimento e do fazer humano. Mesmo no cenário da formação continuada de professores para uma educação decolonial é possível discutirmos o legado freiriano articulado a outras categorias como a da politicidade ou a da gestão democrática, apenas para citarmos alguns exemplos. É possível discutirmos também, em outros momentos, as consequências do estabelecimento de relações entre o pensamento freiriano e a decolonialidade para o desenvolvimento de novas perspectivas acerca do protagonismo da docência para uma educação outra. Trata-se, portanto, de uma temática ampla, diversa e complexa que não se esgota, mas, ao contrário, se espraia e se intensifica na medida em que passa a orientar novas práticas docentes.

\section{Referências}

CORTELLA, M. S. Paulo Freire: um pensamento clássico e atual. Revista e-Curriculum, São Paulo, v. 7, n. 3, p. 1-14, dez. 2011.

DEMO, P. Introdução à metodologia da ciência. São Paulo: Atlas, 1985.

DUSSEL, E. Ética da libertação na idade da globalização e da exclusão. Petrópolis: Vozes, 2000.

FREIRE, P. Quatro cartas aos animadores de Círculos de Cultura de São Tomé e Príncipe. In: BEZERRA, A.; BRANDÃO, C. (org.). A questão política da educação popular. São Paulo: Brasiliense, 1980a. p. 136-196.

FREIRE, P. Conscientização: teoria e prática da libertação: uma introdução ao pensamento de Paulo Freire. São Paulo: Editora Moraes, 1980b.

FREIRE, P. Ação cultural para a liberdade e outros escritos. 5. ed. Rio Janeiro: Paz e Terra, 1981.

FREIRE, P. Pedagogia da esperança: um reencontro com a Pedagogia do oprimido. Rio de Janeiro: Paz e Terra, 1992.

FREIRE, P. A sombra desta mangueira. São Paulo: Olho d'água, 1995. 
O legado de Paulo Freire ao desenvolvimento profissional docente para uma educação decolonial...

FREIRE, P. Pedagogia da autonomia: saberes necessários à prática educativa. São Paulo: Paz e Terra, 1996.

FREIRE, P. Pedagogia da indignação: cartas pedagógicas e outros escritos. São Paulo: UNESP, 2000.

FREIRE, P. A educação na cidade. São Paulo: Editora Cortez, 2001.

FREIRE, P. Pedagogia do oprimido. 44. ed. Rio de Janeiro: Paz e Terra, 2005.

FREIRE, P. Educação como prática da liberdade. 31. ed. Rio de Janeiro: Paz e Terra, 2008.

FREIRE, P.; BETTO, F. Essa escola chamada vida: depoimentos ao repórter Ricardo Kotscho. 9. ed. São Paulo: Ática, 1985.

GADOTTI, M. Lições de Freire. Revista da Faculdade de Educação, São Paulo, v. 23, n. 12, jan./dez. 1997. DOI: https://doi.org/10.1590/s0102-25551997000100002

GARCÍA, C. M. Formação de professores: para uma mudança educativa. Porto: Editora Porto, 1999.

IMBERNÓN, F. Formação docente e profissional: formar-se para a mudança e a incerteza. 6. ed. São Paulo: Cortez, 2011.

IMBERNÓN, F. Formação continuada de professores. Tradução Juliana dos Santos Padilha. Porto Alegre: Artmed, 2010.

IMBERNÓN, F. Formação permanente do professorado novas tendências. Tradução Sandra Trabucco Valenzuela. São Paulo: Cortez, 2009.

LEITE, L. H. A.; RAMALHO, B. B. M.; CARVAlHO, P. F. L. A educação como prática de liberdade: uma perspectiva decolonial sobre a escola. Educação em Revista, Belo Horizonte, v. 35, p. 1-21, e214079, 2019. DOI: https://doi.org/10.1590/0102-4698214079

MIGNOLO, W. Historias locales-diseños globales: colonialidad, conocimientos subalternos y pensamiento fronterizo. Madrid: Akal, 2003.

NÓVOA, A. Professores: imagens do futuro presente. Lisboa: Educa, 2009.

NÓVOA, A. Paulo Freire. In: HOUSSEAYE, Jean. (ed.). Pédagogies contemporains: ‘formation des ensegnants'. Armand Colin: Masson Paris, 1996. p. 48-66.

OCAÑA, A. L. O.; ARIAS, M. I.; CONEDO, Z. E. P. Decolonialidad de la educación: emergencia/urgencia de una pedagogía decolonial. Colômbia: UNIMAGDALENA, 2018.

PONTE, P. O conhecimento profissional dos professores de matemática: relatório final de Projecto "O saber dos professores: concepções e práticas". Lisboa: DEFCUL, 1997.

PONTES, T. P. A.; DI GIORGI, C. A. G. O lugar de Paulo Freire na formação e nos saberes dos professores. Revista Devir Educação, Lavras, v. 4, n. 1, p. 116-138, jan./jun. 2020. DOI: https://doi.org/10.30905/ded.v4i1.162

ROMÃO, J. E. et al. Círculo epistemológico: Círculo de Cultura como metodologia de pesquisa. São Paulo: IPF, 2006. 
WALSH, C. Pedagogías decoloniales: prácticas insurgentes de resistir, (re) existir y (re) vivir. Quito: Abya-Yala, 2013. (Tomo I).

WALSH, C. Interculturalidade crítica e pedagogia decolonial: in-surgir, re-existir e re-viver. In: CANDAU, V. M. (org.). Educação intercultural na América Latina: entre concepções, tensões e propostas. Rio de Janeiro: 7letras, 2009. p. 12-43.

Recebido em 10/08/2020

Versão corrigida recebida em 04/05/2021

Aceito em 08/05/2021

Publicado online em 18/05/2021 